\title{
A importância da utilização da espécie Acmella oleracea L.
}

\author{
Crisna Pereira dos Santos ${ }^{\mathrm{a}^{*}}$, Matheus Mendes Nina ${ }^{\mathrm{a}}$, Sthefanie Felix da Rocha ${ }^{\mathrm{a}}$, Renato Abreu Lima ${ }^{\mathrm{a}}$
}

a Universidade Federal do Amazonas (UFAM), Brasil

*Autor correspondente (crisnap7 @ hotmail.com)

\section{N F O}

Keywords

benefit

jambu

\begin{abstract}
A B S T R A C T
The importance of using Acmella oleracea $\mathrm{L}$.

The use of plant species is what maintains the society in several aspects, enjoying the beneficial properties that biodiversity offers, including among them the vegetable Acmella oleracea L. popularly known as Jambu, being nutritional and commercial value, extracted from the flora. In this way, the work aimed to characterize the importance of this species, showing its properties in various sectors as nutritive functions in food and cosmetics. With its use in certain studies, the article sought to establish the main improvements through bibliographic reviews of certain studies among them, articles, master's studies to doctorates, highlighting its importance and how its flavor that caused dormancy was what made it known. With the revisions of these, it was possible to notice that this species of vegetable is well studied, because it has essential substances that the human body needs, among them, vitamins, calcium, iron and others. Its use has brought to the academic study a different and complementary view and seen in other activities carried out here.
\end{abstract}

\section{R E S U M O}

A utilização de espécies de plantas é o que mantém a sociedade em vários aspectos, usufruindo das propriedades benéficas que a biodiversidade oferece, incluindo entre ela a hortaliça Acmella oleracea L. conhecida popularmente como Jambu, sendo ele valor nutricional e comercial, extraída da flora. Desta forma, o trabalho visou caracterizar a importância desta espécie, mostrando suas propriedades em vários setores como funções nutritivas no alimento e cosmético. O artigo buscou fixar as principais benfeitorias através de revisões bibliográficas de determinados estudos entre eles, artigos, estudos de mestrados até doutorados, destacando a sua importância e como causa sua dormência. Com as revisões destes, foi possível notar que esta espécie de hortaliça é bastante estudada, pois possui substâncias essenciais que o corpo humano necessita, entre elas, vitaminas, cálcio, ferro e entre outros. A sua utilização trouxe para o estudo acadêmico uma visão diferente e complementar jamais vista em outras atividades. 


\section{INTRODUÇÃO}

Considerada uma das famílias de plantas mais ricas em diversidade, esta família conta com cerca de 25.000 a 30.000 espécies, pertencentes a 1.600 a 1.700 gêneros, e apresenta distribuição cosmopolita, não sendo encontrada apenas no continente Antártico (Funk et al. 2009).

No Brasil existem hoje 2.033 espécies de Asteraceae, distribuídas em 278 gêneros, sendo que destas, cerca de 1.310 spp. e 76 gêneros, são endêmicos de nossa flora, ou seja, restritas a determinadas regiões ou localidades do Brasil (Nakajima et al. 2013).

Diante a variedade de espécie, existe entre elas a espécie Acmella oleracea L, conhecida popularmente como Jambu e utilizada para inúmeras funções no ambiente amazônico e apresenta aproximadamente 20 a $30 \mathrm{~cm}$ de altura com caule cilíndrico, carnoso, decumbente e ramificado. Segundo Castro (2016), originário da região amazônica, o jambu é uma hortaliça muito utilizada na culinária do norte do Brasil além da alimentação, a planta é usada pelos povos indígenas e ribeirinhos como analgésico e anestésico para tratar aftas, herpes, dores de dente e garganta.

Segundo Homma (2003), com a criação da Zona Franca de Manaus, em 1967, quando os turistas em busca de produtos importados passaram a visitar Manaus, como se fosse uma Hong Kong da selva. A imagem da Amazônia passou a ser modificada, quando se examina a sua história, verifica-se que a exploração da biodiversidade que precisa ser retirada da redoma utópica que pode ser altamente prejudicial, de forma que se torne uma biopirataria causando o uso de recursos indevidos da biodiversidade.

A importância deste estudo traz a sociedade um retorno de forma que todos saibam a importância que esta espécie traz, como: por exemplo, a respeito de seu consumo e principais utilizações, demonstrando suas vertentes de modo que as características significativas desta espécie sejam destacáveis no segmento que ela é cultivada.

Desta forma, a planta é de grande finalidade para a sociedade, visto isso, o trabalho visa reunir os benefícios da espécie de forma que contemple fatos que demonstrem características não apenas alimentares, mas aspectos gerais da utilização da mesma.

\section{MATERIAL E MÉTODOS}

Quanto ao método de elaboração, as análises foram feitas através de artigos que apresentaram como destaque a espécie Acmella oleracea L. da família Asteraceae que embora seja uma espécie nativa da região amazônica, mostraram-se estudos em outras regiões do Brasil. As especificações foram por meio de seleções do Google Acadêmico.

Durante a seleção foi utilizado os critérios de inclusão de artigos a partir do ano 2000. Utilizando especificações onde possuíam algumas das características botânicas da espécie e onde ela é utilizada. Os artigos foram de caráter de língua portuguesa do Brasil e estrangeira. Foram utilizados artigos das revistas Scielo, Biotemas, Revista Brasileira de Biociências, Ciência Hoje, Embrapa, trabalhos de Pós-Graduação, Mestrados e Doutorado com envolvência desta espécie.

Também foi utilizado vários artigos do Homma (2011), que possui trabalhos voltados para etnocultivo, produção e biopirataria de espécies que compõem a biodiversidade da Amazônia dentre elas o jambu. Utilizou-se análises qualitativas determinando as características da Acmella oleracea L.

\section{RESULTADOS E DISCUSSÃO}

Na maioria das obras bibliográficas de referência são utilizados questionários para a obtenção concisa dos dados, esses questionários avaliativos podem ser de vários tipos em diversas perspectivas e pode utilizar variados métodos amostrais.

De acordo com a obra bibliográfica de Moura et al (2010), por exemplo, "nas análises verificadas nas revisões bibliográficas houve um número amostral de 50 entrevistados" Onde foi considerado um número suficiente após ser verificada a curva de acumulação de espécies, de acordo com o autor mostrou-se estabilizada para o número de espécies vegetais. Visto isso, é necessário verificar o tamanho da população da determinada região, a margem de erro, o nível de confiança e o valor porcentual, pois desta forma, será possível identificar se foi eficaz ou não, no entanto, como o número mostrou-se estabilizado foi observado que a quantidade de questionário foi satisfatória, uma vez que, as respostas dos moradores foram que utilizam e conhecem esta espécie.

As entrevistas em geral possuem caráter estruturado, não estruturado e semiestruturado que de acordo com Kenoby (2019), "diz que estruturado é o artigo que os dados possuem um padrão no qual fica mais fácil para analisar". E o tempo é bem mais utilizado, o não estruturado é um modelo muito mais flexível de entrevista, caracterizando-se pela liberdade dada ao entrevistador.

O semiestruturado encontra-se entre as duas já citadas, é caracterizada por um conjunto de questões previamente estabelecidas, mas, diferente da estruturada, também permite que o entrevistador inclua outro conjunto de questões ao decorrer da entrevista, não planejadas inicialmente. 
As entrevistas utilizadas por Moura et al (2010), "são de caráter não estruturado, pois houve mais tempo para o entrevistado passar a resposta e também um nível maior de maleabilidade", pois deste modo, os moradores puderam dizer se havia ou não a espécie naquela região e também suas outras características.

Sobre a espécie de propriamente dita, de acordo com Nakajima (2014), os estudos verificados apresentam que esta espécie pertence a uma família Asteraceae que é maior da classe Magnoliopsida, ou seja, plantas eudicotiledôneas, que a mesma no que lhe concerne à família que possui mais de 2300 espécimes e se distribuem por regiões tropicais, subtropicais e temperadas de todo o mundo. Mostrando-a diversidade em que se apresenta essa família, com destaque cultural pelo seu sabor exuberante e amortecedor.

O sabor singular e característico da planta faz com que seja uma hortaliça com peculiaridade demasiadamente fácil de ser conhecida, de modo que o consumidor consiga lembrar e distinguir, pois, as suas propriedades se tornam atrativos para o mercado e para o desenvolvimento de estudos científicos.

Demeterco (2016) diz que, o "jambu é tradicionalmente utilizado no preparo de remédios caseiros, como chás e infusões para o tratamento da malária, além de infecções de boca e garganta". Tem propriedades diuréticas e anti-inflamatórias. Em virtude disto a utilização do Jambu está relacionada a remédios caseiros que são de conhecimentos empíricos e por empresas, o conhecimento científico.

O conhecimento empírico que é de costume da população amazonense faz com que os moradores de baixa renda utilizem para remédios de forma que os dois conhecimentos sejam importantes, à medida que o jambu faz parte da gastronomia cultural de determinadas regiões, abrangendo como componentes o pato-no-tucupi e tacacá, que vem sofrendo grandes transformações com relação a sua utilização nas regiões onde há a predominância do cultivo.

Homma (2012), descreve que o jambu possui bom valor nutritivo. "Por cada $100 \mathrm{~g}$ de folhas, contém $89,0 \mathrm{~g}$ de água, valor energético de aproximadamente 32,0 calorias, $1,9 \mathrm{~g}$ de proteína, $0,3 \mathrm{~g}$ de lipídio, 7,2 $\mathrm{g}$ de carboidratos, 1,3 $\mathrm{g}$ de fibra, 1,6 $\mathrm{g}$ de cinza". E também 162,0 $\mathrm{mg}$ de cálcio, 41,0 mg de fósforo, 4,0 mg de ferro, 0,03 $\mathrm{mg}$ de vitamina $\mathrm{B} 1,0,21 \mathrm{mg}$ de vitamina $\mathrm{B} 2,1,0 \mathrm{mg}$ de niacina e 20,0 mg de vitamina C, o jambu é utilizado na composição do creme elixir redutor de rugas da linha Chronos da Natura, que é vendido por R $\$ 128,50$ pela empresa.

Determinando propriedades eficazes, as marcas de cosmético não iriam deixar de usufruir de uma espécie fácil de manejo e benéfico à saúde. Por isso, o conhecimento científico é tão importante quanto o empírico, porque determinada as quantidades benéficas de cada vitamina, fibras, cálcio e entre outros, o conhecimento empírico utiliza sabendo que faz bem, e o científico auxilia determinando como este processo ocorre.

Com todas estas propriedades favoráveis, a sua utilização é decorrente de variedades alimentícias, e sendo um dos pratos principais nos pontos turísticos, e com tantas vitaminas incluídas nela, carrega consigo a importância na fabricação de remédios e cosméticos para a sociedade que por usa vez, a vê apenas para o consumo.

Poltronieri et al., 2000 diz que "o Jambu é uma planta anual herbácea, com caule cilíndrico, carnoso, decumbente e ramificado. A inflorescência é em um capítulo globoso terminal de coloração amarela, com floretas hermafroditas". A flor é considerada como autopolinizadora, ocorrendo quando o estilete cresce e ultrapassa as anteras e, ao despontar no exterior os estigmas já se encontram cheios de pólen. Sendo uma vez, polinizadora nos determina que ajuda a manter o equilíbrio ecológico, pois ocorre polinização direta.

Homma (2012), "relata que inicialmente as plantas eram adquiridas em Belém, foi visto que a partir de 2004, passou a ser fornecido pelo Grupo Centroflora, fundado em 1957" com produtores selecionados que cultivam de forma orgânica nos municípios de Pratânia, Botucatu (onde efetua a secagem), Ribeirão Preto e Jaboticabal.

Com tanta importância destacada a espécie possui em seu histórico várias teses de pós-graduação sobre o jambu e já foram defendidas nas universidades do sul e sudeste, facilitando, também, na disseminação desta planta, determinando que ela é suma importância em todas as esferas. Uma espécie de hortaliça nativa da Amazônia faz se pensar por que há estudos em outras regiões?

Possivelmente a interferência de políticas públicas no que se tange a espécie faz com que existam tantos estudos para as demais regiões, nas quais haja o investimento para o apoio e parcerias de laboratórios apropriados para pesquisas, o que fortalece ainda mais a aplicação de estudos de ponta para regiões no qual existam recursos para a investigação, diferente nas demais regiões onde não há essa possibilidade, que não possuem uma estrutura e nem estados que possuem a renda per capita que facilite.

Homma (2012), também diz que, "o alcalóide spilanthol, é o que causa uma leve dormência, presente nas folhas, ramos e flores do jambu é descrito em patentes como apropriado para uso anestésico" também antisséptico, antirrugas, anti-inflamatório, creme dental, ginecológico, com diversos produtos 
no mercado, vendidos como remédio e cosmético. Com determinada propriedade específica suas características não foram vistas somente a olhos nacionais, mas também mundialmente, o que favorece economicamente a produção de produtos e alimentos que pode ajudar aqueles que vivem apenas de agricultura.

De acordo com Homma (2012), "o ciclo do jambu depois de plantado no canteiro dura de 25 a 30 dias até ser arrancado e média seja acima de $15^{\circ} \mathrm{C}$ ". Já os solos indicados para o cultivo dessa hortaliça devem ser argilosos arenosos e ricos em matéria orgânica. Porém, vale ressaltar que solos de várzea, quando bem drenados podem, também, ser utilizados para o cultivo do jambu. Desta forma, é possível observar que embora seja aparentemente fácil o manejo é necessário um cuidado eficaz no seu cultivo para que todas as propriedades da erva sejam preservadas.

Com as observações bibliográficas foram possíveis destacar a utilização de análises verificada, onde estudos ocorreram na Área de Proteção Ambiental dos Pirineus. Segundo Moura et al (2010), "a área com 22.800 hectares (criada pelo decreto $\mathrm{n}^{\circ}$ 5.175 de 17 de fevereiro de 2000), e o Parque estadual dos Pirineus, com 2.822 hectares, ambos situados em Goiás". Com características de climáticas é caracterizado por duas estações bem definidas.

As revisões bibliográficas também foram de material botânico utilizado estudo obtido de flores e botões florais retirados de exsicatas depositadas no Herbário da Universidade Estadual de Ponta Grossa (HUPG), Paraná, Brasil. Sendo então, a pesquisa realizada na seleção das espécies de Asteraceae mais utilizadas, de acordo com Staniski et al. (2014), "medicinalmente na região dos Campos Gerais a partir de levantamento realizado no Herbário HUPG".

Diante as análises bibliográficas foram possíveis verificar que a espécie Acmella oleracea L. é utilizada não somente para a culinária em decorrência a viés turísticos, mas também medicinal que traz benefícios para quem a utiliza de várias multiplicidades, mostrando-nos também que por ser da região amazônica não determina limites para estudos, mas que também em diferentes regiões é cultivada e estudada.

\section{CONCLUSÕES}

O estudo bibliográfico aqui apresentado traz uma reflexão sobre aspectos gerais da espécie. Discute formas de melhor combater a biopirataria na Amazônicas entre elas, a necessidade em transformar os recursos da biodiversidade em atividades econômicas sustentáveis para geração de emprego e renda para a população.
Esta espécie de hortaliça mostra que pode ser mais que um prato feito com viés turísticos, mas que bem estudada e investida no manejo pode trazer benefícios para as indústrias farmacêuticas pelos seus potenciais característicos de vitaminas, cálcios, ferros e entre outros eficazes para a saúde humana.

Portando com tantas propriedades favoráveis, o lugar de estudos e pesquisas vem de regiões diferentes do local nativo da espécie, o que pode se tornar uma nova conversa para a distribuições igualitárias de políticas públicas, de forma que o repasse de investimentos de pesquisas para um determinado estado seja de forma coerente, onde todos possam ter a mesma capacidade de investigar e usufruir de nutrientes que determinada espécie possui.

\section{REFERÊNCIAS BIBLIOGRÁFICAS}

BERETTA, M.E. et al. A família Asteraceae no Parque Estadual de Itapuã, Viamão, Rio Grande do Sul, Brasil. Revista Brasileira de Biociências, Rio Grande do Sul, v.6, n.3, p.189-216, 19 abr. 2009.

CASTRO, K.N.C.; ANHOLETO, L.A. et al. Cytotoxic effects of extract of Acmella oleraceae (Jambu) in rhipicephalusmicroplus females ticks. Microscopy research and technique. On-line. ago. 2016.

DEMETERCO, C. Slow food brasil Jambú. 2016. Disponível em: <http://www.slowfoodbrasil.com/arca-do-gosto/produtos-do-brasil/1123-jambu>. Acesso em: 16 maio 2019.

HOMMA, A.K.O. et al. Etnocultivo do Jambu para abastecimento da cidade de Belém, estado do Pará. Amazonia Ciencia \& Desenvolvimento, Belém, n.6, p.125-141, 12 jun. 2011.

HOMMA, A.K. O. História da agricultura na Amazônia: da era pré-colombiana ao terceiro milênio. Brasília, DF: Embrapa Informação Tecnológica, 2003. 274 p. Disponível em: http://pt.espacenet.com. Acesso em: 18 mai. 2019.

HOMMA, A.K.O. "Plant extractivism or plantation: what is the best option for the Amazon?" Estudos Avançados. 2012; v.26, n.74, p.167-186.

FREITAS BLANCO, V.S., FRANZ-MONTAN, M. et al. Development and evaluation of a novel mucoadhesive film containing Acmella oleracea extract for oral mucosa topical anesthesia. PLOS ONE. On-line. set. 2016.

KENOBY. Tipos de entrevista: estruturada, semiestruturada e não estruturada. 2019. Disponível em: <http://www.kenoby.com/blog/tipos-de-entrevista/>. Acesso em: 18 maio 2019.

SILVA, A.A.; ANDRADE, L.H.C. Utilização de espécies de Asteraceae por comunidades rurais do nordeste do Brasil: relatos em Camocim de São Félix, Pernambuco. Biotemas, [s.1.], v.26, n.2, p.94-102, 4 mar. 2013. Universidade Federal de Santa Catarina (UFSC).

http://dx.doi.org/10.5007/2175-7925.2013v26n2p93. 
MINISTÉRIO DA SAÚDE. Manual operacional para comitês de ética em pesquisa. Brasília: Conselho Nacional de Saúde, 2002.

MOURA, I.O.; GOMES-KLEIN, V.L.; FELFILI, J.M., FERREIRA, H.D. 2010. Diversidade e estrutura comunitária de cerrado sensu stricto em afloramentos rochosos no Parque Estadual, Goiás. Revista Brasileira de Botânica, v.33, n.3, 455-467.

NAKAJIMA, J.N.; PACHECO, R.A. A família Asteraceae na Serra dos Pireneus, Goiás, Brasil. 2014. 181 f. Dissertação (Mestrado) - Curso de Biologia Vegetal, Programa de Pós-graduação, Universidade Federal de Uberlândia, Uberlância, 2014.

POLTRONIERI, M.C., MÜLLER, N.R.M., POLTRONIERI, L.S. Recomendações para a produção de jambu: cultivar Nazaré. Embrapa Amazônia Oriental, 2000.

STANISKI, A., FLORIANI, N., STRACHULSKI, J. 2014.

Estudo etnobotânico de plantas medicinais na comunidade faxinalense Sete Saltos de Baixo, Ponta Grossa - PR.

Terr@Plural,v.8, p.321-240. 